\title{
Road Traffic Accident: An Emerging Epidemic
}

\author{
Naresh Kumar Yadav \\ BPH $24^{\text {th }}$ Batch
}

\begin{abstract}
An accident has been defined as an unexpected unplanned occurrence which may involve injury. Accidents represent a major epidemic of non-communicable disease in the present century. Since the advent of vehicles, the number of road traffic accident has risen proportionate to the number of vehicles manufactured .The term killed (in an RTA) is defined as any person who was killed outright or who died within 30 days as a result of accident (WHO 1984). Road traffic injuries kill about 3000 people and 30000 are injured and disabled for life every day. Developing countries account for $90 \%$ of global road traffic deaths. In Nepal, as per estimates of morbidity and mortality for injury contributed $9 \%$ to total mortality.
\end{abstract}

In a country like ours, with poor roads, ill-managed vehicles, improper rash driving, highway being the sites for play of children and inadequate teaching of traffic rules to drivers as well as its inadequate incorporation in school curriculum leads to increased involvement of children in Road Traffic Accident (RTA) is one among the top five causes of morbidity and mortality in South-East Asian countries.

In fact, road traffic injuries alone ranked as the number one cause of disease burden among children between 5 and 14 years, and as the number three cause among those in the age group 15 to 29 years with a male female ratio of $3: 1$. Most commonly affected road users are pedestrians, passengers and cyclists as opposed to drivers who are involved in most of the deaths and disabilities.

\section{Accident chart}

Total number of accident in kathmandu

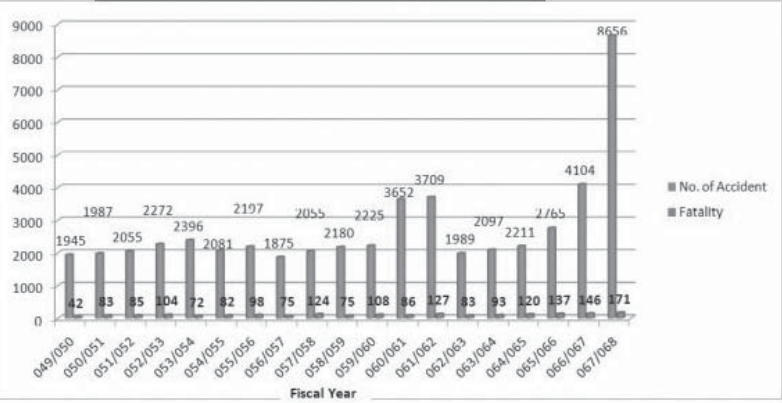

Common factors associated in RTA are:-

\section{Sociodemographic factors and RTA}

Age, sex, family type, residence, education and socioeconomic break ups: most cases $38.33 \%$ were in the age group of 15-30 years. Most of the cases were from joint family i.e. $68.61 \%$. Victims from rural areas $65.83 \%$ were more as compared to urban areas. High prevalence of RTA was reported in school educated i.e. $49.16 \%$ and graduates $39.1 \%$ People from middle and low socioeconomic class were also affected more i.e. $55 \%$ and $31.66 \%$, respectively.

\section{Human factor in RTA}

Personal history and RTA: Personal problems like deviance, hyperactivity, low tolerance, inattentiveness were associated with $33.33 \%$ RTA cases. Alcohol consumption and RTA: 'Alcohol - the killer on road' is a well documented fact.

Disease conditions and RTA: Out of the total RTA cases $8.33 \%$ were found to have disease conditions like diabetes, hypertension, tuberculosis etc.

\section{Types of victims and RTA}

Road users in RTA: $42.50 \%$ were passengers, $29.16 \%$ pedestrians, $19.17 \%$ drivers and $9.61 \%$ cyclists.

\section{Time factors in RTA}

Maximum number of accidents occurred in between 3 and 7 p.m. i.e. $44.16 \%$ followed by $24.16 \%$ between 7 and 11 a.m. Mortality wise highest number of cases were found between 3 and 11p.m. at a percentage of $72.72 \%$. The distributions of non-fatal cases were maxi mum from 3 to 7 p.m. $44.8 \%$

\section{Environmental factors and RTA}

A study was observed that $81.66 \%$ RTA occurred in rainy and cloudy conditions. Most of the accidents occurred at the starting of the journey i.e. 55\% and the trend again picked at the fag end of the journey i.e.19.16\% It was observed that $50 \%$ cases were due to high speeding vehicles $(40-60 \mathrm{~km} / \mathrm{h}$.).

\section{Road condition and RTA}

Narrow and wide: $59.16 \%$ of accidents were collision type and $40.83 \%$ were non-collision type. Narrow and defective roads were responsible for non-collision accidents where as collision types occurred mostly in wide roads i.e. Noncollision accidents like running of the road, overturning, knocking down of pedestrians were found to be significantly 
associated with narrow and defective road conditions.

About $85 \%$ of RTA occurred in familiar roads to that of $14.17 \%$ in non-familiar ones. The collision and non collision types in familiar road conditions.

\section{Traffic conditions and RTA}

Traffic police: Only $5.83 \%$ occurred in presence of the traffic police.

Traffic light: Only 5\% cases of RTA occurred in the presence of effective traffic light. The mortality and morbidity percentage were similarly low in the presence of traffic and effective traffic light.

\section{Vehicle condition}

Age of the vehicle: $65.85 \%$ RTA was observed in old and $34.14 \%$ were new. Fatal accidents caused by motor vehicles, $78.57 \%$ were due to old ones. Old vehicles were also responsible for majority of non-fatal accidents i.e. $43.67 \%$

\section{Prevention and control}

The incidence and impact in road traffic injuries, accidents and deaths are reduced by following intervention by improving the:-

\section{Socioeconomic condition.}

$1 \quad$ Educating public through the mass media

$1 \quad$ Initiating road safety training campaign in schools

1 Government policy to restrict alcohol consumption

$1 \quad$ Social and political stability

\section{Road condition}

$1 \quad$ Widening a narrow section of road

$1 \quad$ Improvement in road lighting

$1 \quad$ Making and enforcing policy to reduce number of luxurious vehicles

$1 \quad$ Promote limited safe public vehicles

$1 \quad$ Segregation of different type of road users

$1 \quad$ Building of overpass (flyover) or underpass

\section{Vehicle condition}

1 Provision of seat belts in vehicles

1 Change in the design or construction of vehicles as the condition of road, density of population

$1 \quad$ Proper and timely maintenance of vehicles

1 Provision of proper site for vehicle station

1 Removal of sharp and dangerous projection from vehicles to reduce the interior or exterior injuries.

\section{Road user condition}

$1 \quad$ Licensing of drivers

$1 \quad$ Training of drivers

1 Safety education

$1 \quad$ Setting and enforcing mandatory crash helmet use
$1 \quad$ Legislation to control speed of vehicle

\section{Service care}

$1 \quad$ Pre hospital care (first aid services)

1 Emergency care of injured patients of RTA

1 Establishment of rehabilitation centre for handicapped patients of RTA

Interventions in TRA are broad-based and include regulation, legislation and community projects. The government of Nepal should find ways to support policy at local level. This should be client-oriented with good community support so as to overcome limitations. The focus should be on issues like establishment of Provincial Safety Committee, Motorcycle Helmet Campaign, Anti-DrunkDriving Campaign, Traffic Injury Prevention in School, Safe Communities and establishment of trauma registry and the Pre-hospital Care System.

However, partnerships need to be formed with public, private and non-governmental organizations to address more visibly the problems and press harder for improvements. Political leadership, good governance, policy support and a reliable technical team are the key components on which Nepal should be zeroing in.

\section{References}

1. Annual Report of the Department of Health Services Nepal, 2006

2. World Health Report on Prevention of Accidents. Geneva: WHO; 2004

3. WHO, Road traffic accidents in developing countries.

4. Central bureau of statistics. Kathmandu, Nepal

5. Traffic police, Ministry of Home, Nepal 